\title{
Opportunities for diabetes research using the Norwegian Cardiovascular Disease Registry
}

\author{
Grace M. Egeland ${ }^{1,2}$, Vernar Sundvor ${ }^{1}$, Jannicke Igland ${ }^{1,2}$, Ingvei Seliussen ${ }^{1}$, Yngve Klakegg ${ }^{1}$, \\ Stein Emil Vollset ${ }^{1,2}$, Rupali Akerkar ${ }^{1}$, Grethe S. Tell ${ }^{1,2}$ and Marta Ebbing ${ }^{1}$ \\ 1) Norwegian Institute of Public Health (NIPH), Kalfarveien 31, 5018 Bergen, Norway \\ 2) Department of Global Public Health and Primary Care, University of Bergen, Kalfarveien 31, Bergen, Norway
}

Correspondence: Grace M. Egeland, e-mail: g.egeland@igs.uib.no; telephone: +47 53204065

\begin{abstract}
While Norway has many outstanding health registries that are used as a foundation for surveillance, quality control and epidemiologic research, it was recognized that a knowledge gap existed regarding the prevalence, incidence, and quality of health care delivery for cardiovascular diseases (CVD) which remains the primary cause of death in the country. Given broad agreement for the need for a registry by patient organizations, research environments and health authorities, the Norwegian Parliament decided to establish the Norwegian Cardiovascular Disease Registry (NCVDR) in March 2010 and then adopted new regulations in December 2011 which established the NCVDR. The registry consists of a core registry housed and maintained by the Norwegian Institute of Public Health (NIPH) that is supplemented with information from the medical quality registries housed and maintained by the hospital trusts. Given the burden of CVD among patients with diabetes and the unique challenges of medical care for CVD patients with diabetes, the registries also provides a new opportunity to advance diabetes research in Norway.
\end{abstract}

\section{INTRODUCTION AND DIABETES RESEARCH POTENTIAL OF THE NORWEGIAN CVD REGISTRY}

While there is evidence of declining mortality for acute myocardial infarction (1), CVD remains the leading cause of mortality in Norway $(1,2)$. Further, there are concerns that the declining trend in CVD mortality may not be sustainable, reflective of subpopulations, or of disease burden. For example, there is evidence of increasing obesity and diabetes prevalence rates (3), and of an increasing incidence of acute myocardial infarction (MI) in women in Tromsø (4). Further, hospitalization rates for CVD do not reflect the same downward trend as that observed for CVD mortality (5), and hospitalizations for acute MI for those over 79 years of age have not been declining (6).

While the burden of diabetes in Norway is not known, an estimated 3-5\% of the Norwegian population has diabetes mellitus with prevalence peaking at 11$12 \%$ for those $80-89$ years of age $(3,7-9)$. Diabetes mellitus is associated with a two- to four-fold increased risk of cardiovascular diseases including coronary heart disease, stroke, atrial fibrillation and flutter, and left ventricular hypertrophy (10-13). Both type 1 and type 2 diabetes mellitus are associated with excess CVD risks (14), and approximately $2 / 3$ rds of diabetic patients suffer from cardiovascular disease (15-19), posing unique challenges in the treatment and management of patients.

A priority research arena is to elucidate best practice for the integrated care of patients with diabetes, particularly for those with cardiovascular complications. Data sources in Norway could provide an opportunity to advance this arena of research in which large population-based registries with comprehensive data on clinical management and outcomes could provide an opportunity to make meaningful contributions to the literature. An example of a research arena requiring further investigation is the extent to which CVD complications among diabetic patients is related to the degree of glycemic control (20). The efficacy of glycemic control interventions has not been observed for all CVD sequelae (21) and there is considerable uncertainty regarding the nature of the glycemic control and CVD dose-response relationship (22-24). Further, diabetes represents a challenge to health care practitioners and patients alike in that intensive efforts to control hyperglycemia may potentially introduce competing risks. The Action to Control Cardiovascular Risk in Diabetes Study found increased mortality and no significant reduction in cardiovascular disease events in the intensive intervention group (24). Research findings, thus far, have led to recommendations against overly strict glycemic control (25).

Another example of research promoting improved health care delivery for patients with diabetes was the finding of a nearly 4-fold excess risk of CVD observed among diabetic patients with prehypertension (systolic blood pressure of 120-139 $\mathrm{mmHg}$ and/or a diastolic blood pressure of $80-89 \mathrm{mmHg}$ ) (26) which has led to new recommendations for blood pressure control among diabetic patients. Another important research arena is the exploration of potential differences in drug efficacy in patients with and without diabetes (27-29). Finally, the extensive variability in the continuum of the diabetic condition needs to be considered in the evaluation of primary and secondary intervention approaches (30). The above mentioned illustrations provide a few examples regarding the need for ongoing clinical epidemiological research for identifying best practices in the treatment of patients with diabetes. 


\section{BACKGROUND ON THE NORWEGIAN Cardiovascular Disease Registry (NCVDR) AND LEGAL MANDATE}

The advantages of epidemiological research in Norway is well known given our national health care system, registries, and ability to link between data sources based upon the unique identification number of individuals. The formation of the Norwegian Cardiovascular Disease Registry (NCVDR) extends these epidemiological research opportunities to cardiovascular diseases. Given broad agreement for the need for a registry by patient organizations, research environments and health authorities, the Norwegian Parliament decided to establish the Norwegian CVD Registry in March 2010 and formally adopted new regulations on December 16, 2011 which established the Registry with data collection commencing in January 2012 (31,32). In accordance with the statutory authority of the Health Register Law Act $\$ 8$, the legislation established the NCVDR as a nationwide registry in which personal identification of patients can be collected without the requirement for informed consent from those registered in order to meet the goals of the registry; the legislation expanded the Norwegian Institute of Public Health's (NIPH) disease surveillance mandate. The NIPH has data management responsibility and judicial responsibility for safeguarding patient privacy and confidentiality of patient information for the registry in accordance with applicable laws and regulations $(32,33)$. Further, identifying information on individuals is removed from files used for analyses once a unique number is assigned to each person. This unique number enables researchers to generate health statistics without concern of duplicate enumeration of CVD events and makes it possible to track the same patient over time and from hospital to hospital.

The NCVDR consists of a core registry housed and maintained by the Bergen Division of the NIPH. A collaborative agreement is being finalized between NIPH and St. Olav's Hospital Trust to formalize the inclusion of clinical information collected by the medical quality registries, such as the Norwegian Myocardial Infarct Registry (34) and the Norwegian Stroke Registry (35). The inclusion of data from the medical quality registries will provide details regarding the variable manifestations of cardiovascular disease, risk factors, co-morbidities, treatment and their results. In the future, it is anticipated that the NCVDR will also include information collected by primary care physicians, which would provide additional information for CVD patients with diabetes, such as glycemic control.

\section{OBJECTIVES}

There are four primary objectives of the NCVDR:

1. to provide comprehensive data regarding the incidence and prevalence of CVD;

2. to evaluate the prognosis of patients by relevant diagnostic categories and treatment modalities;
3. to provide a means of supporting basic clinical research to enhance the quality of health care delivery;

4. to provide evidence-based knowledge for primary and secondary prevention and health care planning.

\section{About The Registry AND COLLABORATIONS BETWEEN NIPH AND THE HOSPITAL TRUSTS}

The NCVDR is based upon the collaborative organizational model, which has been described in the report "Good Health Registries - Better Health" (36), in which the government seeks to register information from a variety of sources for important diseases and medical conditions for improving disease surveillance and ultimately health care delivery and primary prevention strategies. By combining data resources into one nationwide CVD registry, we will have greater oversight and a greater likelihood of reducing the burden of disease in the population.

The core NCVDR will consist of data of cardiovascular disease patients identified starting Jan 1, 2012 from the Norwegian Patient Registry (37) and Cause of Death Registry (38), with supplemental information from the Central Population Registry (39) (Figure 1). CVD patients will be identified using the relevant ICD-10 codes associated with CVD (40) (Table 1). Patients will be included in the registry if they were discharged from hospital or out-patient clinics with one of the listed diagnostic codes (as main or secondary diagnoses). In addition, all the deceased with any CVDrelated diagnose as the underlying or contributing cause of death, will be included in the registry.

Of note for diabetes researchers is that the ICD-10 codes for diabetes found in ICD-10 Chapter IV regarding endocrine, nutritional, and metabolic disorders are not used as qualifying criteria for inclusion in the

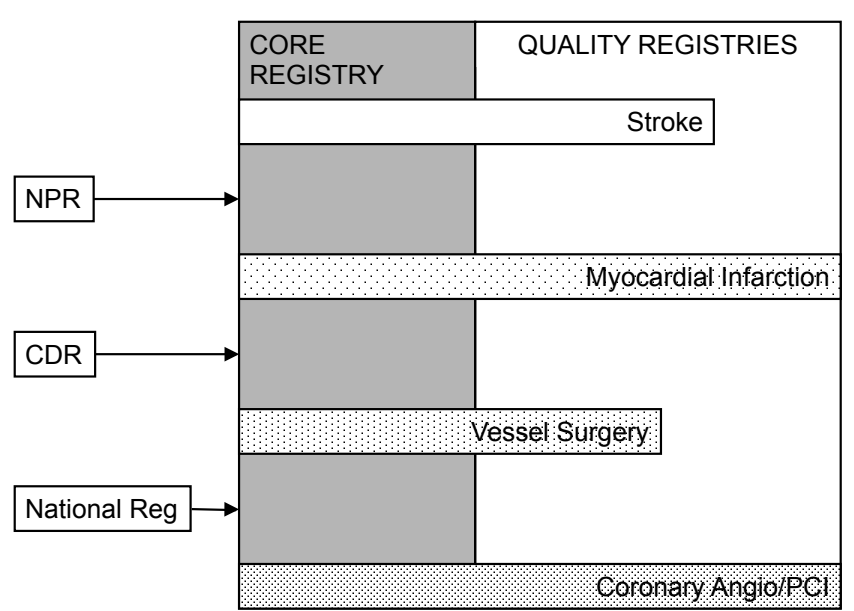

Figure 1. Diagram of the Norwegian Cardiovascular Disease Registry (NCVDR) Components. Abbreviations: NPR, National Patient Registry; CDR, Cause of Death Registry; National Reg, National Population Registry. 
Table 1. Qualifying International Classification of Disease (ICD-10) Codes utilized for identifying patients for inclusion in the Norwegian Cardiovascular Disease Registry.

\begin{tabular}{|c|c|c|}
\hline $\begin{array}{l}\text { ICD-10 } \\
\text { Chapter }\end{array}$ & $\begin{array}{l}\text { Category } \\
\text { Codes }\end{array}$ & Diagnoses \\
\hline I & A00-B99 & Certain infections and parasitic diseases \\
\hline II & $\mathrm{C} 38$ & Malignant neoplasm of heart \\
\hline II & D15 & Benign neoplasm of other and unspecified intrathoracic organs \\
\hline V & F01 & Vascular dementia \\
\hline VI & G45 & Transient cerebral ischeamic attacks and related syndromes \\
\hline VI & G46 & Vascular syndromes of brain in cerebrovascular diseases (I60-I67) \\
\hline VII & H34 & Retinal vascular occlusions \\
\hline IX & I00-I99 & Diseases of the circulatory system \\
\hline XI & K55 & Vascular disorders of intestine \\
\hline XIV & N28 & Other disorders of kidney and ureter, not elsewhere classified \\
\hline $\mathrm{XV}$ & $\mathrm{O} 10-\mathrm{O} 16$ & Oedema, proteinuria and hypertensive disorders in pregnancy, childbirth and the puerperium \\
\hline $\mathrm{XV}$ & $\mathrm{O} 20-\mathrm{O} 29$ & Other maternal disorders predominantly related to pregnancy \\
\hline $\mathrm{XV}$ & O89 & Complications of anaesthesia during the puerperium \\
\hline $\mathrm{XV}$ & O90 & Complications of the puerperium, not elsewhere classified \\
\hline $\mathrm{XV}$ & O99 & $\begin{array}{l}\text { Other maternal diseases classifiable elsewhere but complicating pregnancy, childbirth and the } \\
\text { puerperium }\end{array}$ \\
\hline XVI & $\mathrm{P} 00$ & Fetus and newborn affected by maternal conditions that may be unrelated to present pregnancy \\
\hline XVI & P10 & Intracranial laceration and haemorrhage due to birth injury \\
\hline XVI & $\mathrm{P} 25$ & Interstitial emphysema and related conditions originating in the perinatal period \\
\hline XVI & P29 & Cardiovascular disorders originating in the perinatal period \\
\hline XVI & P52 & Intracranial nontraumatic haemorrhage of fetus and newborn \\
\hline XVII & Q20-Q28 & Congenital malformations of the circulatory system \\
\hline XVIII & R00-R09 & Symptoms and signs involving the circulatory and respiratory systems \\
\hline XVIII & $\mathrm{R} 23$ & Other skin changes \\
\hline XVIII & R55-R69 & General symptoms and signs \\
\hline XVIII & R90-94 & Abnormal findings on diagnostic imaging and in function studies without diagnosis \\
\hline XVIII & R95-R99 & Ill defined and unknown causes of mortality \\
\hline XIX & S00-S99 & Injuries (heart and large vessels) \\
\hline XIX & $\mathrm{T} 80-\mathrm{T} 88$ & Complications of surgical and medical care, not elsewhere classified \\
\hline $\mathrm{XX}$ & Y60-Y69 & Misadventures to patients during surgical and medical care \\
\hline $\mathrm{XX}$ & Y70-Y82 & Medical devices associated with adverse incidents in diagnostic and therapeutic use \\
\hline $\mathrm{XX}$ & Y83-Y84 & $\begin{array}{l}\text { Surgical and other medical procedures as the cause of abnormal reaction of the patient, or of later } \\
\text { complication, without mention of misadventure at the time of the procedure }\end{array}$ \\
\hline XXI & Z00-Z13 & Persons encountering health services for examination and investigation \\
\hline XXI & Z40-Z54 & Persons encountering health services for specific procedures and health care \\
\hline XXI & Z80-Z99 & $\begin{array}{l}\text { Persons with potential health hazards related to family and personal history and certain conditions } \\
\text { influencing health status }\end{array}$ \\
\hline
\end{tabular}

Source: World Health Organization, International Classification of Disease-10, Version 2010, English.

Available at: http://apps.who.int/classifications/icd10/browse/2010/en

CVD Registry. Instead, the ICD-10 codes associated with diabetes are to be available only among patients with the CVD-related qualifying diagnoses noted in Table 1. Many patients with diabetes will have additional CVD diagnoses when being hospitalized, and many CVD patients will have diabetes as a secondary diagnosis.

The NCVDR will also collect information from the medical quality registries for selected conditions and procedures, including stroke, myocardial infarction, and vessel surgery, and, pending approvals, coronary angiography and percutaneous coronary intervention (PCI).

\section{DIABETES RESEARCH OPPORTUNITIES}

Given the burden of CVD among diabetic patients and the unique challenges they pose for clinicians, the formation of the NCVDR provides an opportunity to engage in research that will ultimately improve our understanding and clinical care for this high-risk patient population. We foresee the development of research projects comparing the prognosis for CVD patients with and without diabetes. Further, we foresee future data linkages between the NCVDR and other data sources for evaluating specific questions that can not 
Table 2. Data sources of relevance for diabetes research in Norway.

\begin{tabular}{lll}
\hline Data Source & Description & Ref \\
\hline Norwegian Childhood Diabetes Registry & Type 1 diabetes diagnosed before age 15 & 43 \\
The Norwegian Diabetes Registry for Adults & Adults with type 1 or 2 diabetes. Not yet national in scope & 44 \\
Other medical quality registries (e.g., Myocardial & Regarding important co-morbidities & 34,35 \\
Infarct Registry and Stroke Registry) & & 41 \\
National Prescription Registry (NorPD) & Dispensed drugs & 42 \\
Cohort Norway (CONOR) and Regional Health & Population-based health screening & 32 \\
Screening Surveys & & National Patient Registry, Cause of Death Registry, and \\
Norwegian Cardiovascular Disease Registry (NCVDR) & National Population Registry \\
\hline
\end{tabular}

be addressed based upon the NCVDR or other data sources alone. For example, linkages between the NCVDR and the National Prescription Registry (NORPD) (41) could form a database for evaluating pharmacological treatment modalities and prognosis relative to the range and severity of co-morbidities of relevance to diabetes. We also foresee opportunities to link Cohort of Norway (CONOR) or the individual Regional Health Survey Screening study populations (42) with the NCVDR for prospective evaluation of baseline risk factors for their association with CVD incidence and mortality for those with and without diabetes. Further, future data linkages between the NCVDR and the Norwegian Diabetes Registry (43) provides an opportunity to evaluate CVD sequelae for this important patient population. The Norwegian Diabetes Registry contains all registered type 1 diabetes cases diagnosed before age 15 years identified retrospectively beginning in 1973 and identified prospectively since 1989. Likewise, the ongoing development of a nationwide adult diabetes medical quality registry, initiated in 2006 (44), will provide important details regarding medical care, glycemic control, and comorbidities which, through data linkages with the NCVDR, will represent a significant resource for both type 1 and type 2 diabetes research in Norway.

Also, the data provided by other medical quality registries will enable a detailed evaluation of the range of comorbidities, and the prognosis for diabetic patients following vessel surgery or coronary angiography or PCI procedures. These are examples of the synergistic research opportunities that are to emerge once the NCVDR is operational.

A similar model of research in Denmark, for example, allowed for linking patients with nationwide administrative registries of dispensed prescriptions, hospitalizations, and cause of death. The record linkages enabled the evaluation of the efficacy of clopidogrel treatment following myocardial infarction in which the risk reduction for diabetics was lower than that observed for non-diabetic patients (28). Diabetic patients have increased platelet activity and despite clopidogrel treatment have high platelet activity (45, 46). These and other research findings speak to the need for identifying appropriate risk reduction strategies for CVD patients with diabetes.

The information gleaned from such future research will help provide the clinical epidemiological framework for improving the quality of health care delivery for Norway's high-risk CVD patients with diabetes.

\section{REFERENCES}

1. Reikvam A, Hagen TP. [Changes in myocardial infarction mortality.] Tidsskr Nor Lageforen 2011; 131: 46870.

2. Statistics Norway. Causes of Deaths, 2010. Statistics Norway, 2011.

3. Midthjell K, Kruger O, Holmen J, Tverdal A, Claudi T, Bjorndal A, et al. Rapid changes in the prevalence of obesity and known diabetes in an adult Norwegian population. The Nord-Trondelag Health Surveys: 19841986 and 1995-1997. Diabetes Care 1999; 22: 1813-20.

4. Mannsverk J, Wilsgaard T, Njolstad I, Hopstock LA, Lochen ML, Mathiesen EB, et al. Age and gender differences in incidence and case fatality trends for myocardial infarction: a 30-year follow-up. The Tromso Study. Eur J Prev Cardiol 2012; 19: 927-34.

5. Oyen N, Nygard O, Igland J, Tell GS, Nordrehaug JE, Irgens LM, et al. [Hospital admission rates for cardiovascular diseases in Western Norway, 1992-2001]. Tidsskr Nor Laegeforen 2008; 128: 17-23.

6. Reikvam A, Hagen TP. Markedly changed age distribution among patients hospitalized for acute myocardial infarction. Scand Cardiovasc J 2002; 36: 221-4.

7. Strom H, Engeland A, Eriksen E, Sakshaug S, Ronning M. [How many and who are receiving medication for diabetes mellitus?]. Tidsskr Nor Lageforen 2006; 126: 768-70. 
8. Stene LC, Midthjell K, Jenum AK, Skeie S, Birkeland KI, Lund E, et al. [Prevalence of diabetes mellitus in Norway]. Tidsskr Nor Lageforen 2004; 124: 1511-4.

9. Midthjell K, Bjorndal A, Holmen J, Kruger O, Bjartveit K. Prevalence of known and previously unknown diabetes mellitus and impaired glucose tolerance in an adult Norwegian population. Indications of an increasing diabetes prevalence. The Nord-Trondelag Diabetes Study. Scand J Prim Health 1995; 13: 229-35.

10. Sowers JR, Epstein M, Frohlich ED. Diabetes, hypertension, and cardiovascular disease: an update. Hypertension 2001; 37: 1053-9.

11. Beckman JA, Creager MA, Libby P. Diabetes and atherosclerosis: epidemiology, pathophysiology, and management. JAMA 2002; 287: 2570-81.

12. Rosamond W, Flegal K, Friday G, Furie K, Go A, Greenlund K, et al. Heart disease and stroke statistics 2007 update: a report from the American Heart Association Statistics Committee and Stroke Statistics Subcommittee. Circulation 2007; 115: e69-171.

13. Movahed MR, Hashemzadeh M, Jamal MM. Diabetes mellitus is a strong, independent risk for atrial fibrillation and flutter in addition to other cardiovascular disease. Int J Cardiol 2005; 105: 315-8.

14. Juutilainen A, Lehto S, Ronnemaa T, Pyorala K, Laakso M. Similarity of the impact of type 1 and type 2 diabetes on cardiovascular mortality in middle-aged subjects. Diabetes Care 2008; 31: 714-9.

15. Claudi T, Midthjell K, Holmen J, Fougner K, Kruger O, Wiseth R. Cardiovascular disease and risk factors in persons with type 2 diabetes diagnosed in a large population screening: the Nord-Trondelag Diabetes Study, Norway. J Intern Med 2000; 248: 492-500.

16. Dale AC, Nilsen TI, Vatten L, Midthjell K, Wiseth R. Diabetes mellitus and risk of fatal ischaemic heart disease by gender: 18 years follow-up of 74,914 individuals in the HUNT 1 Study. Eur Heart J 2007; 28: $2924-9$.

17. Naess S, Eriksen J, Midthjell K, Tambs K. Diabetes mellitus and comorbidity. Change between 1984-1986 and 1995-1997: results of the Nord-Trondelag Health Study. J Diabetes Complicat 2003; 17: 323-30.

18. Dale AC, Vatten LJ, Nilsen TI, Midthjell K, Wiseth R. Secular decline in mortality from coronary heart disease in adults with diabetes mellitus: cohort study. BMJ 2008; 337: a236.

19. Iversen MM, Tell GS, Riise T, Hanestad BR, Ostbye T, Graue M, et al. History of foot ulcer increases mortality among individuals with diabetes: ten-year follow-up of the Nord-Trondelag Health Study, Norway. Diabetes Care 2009; 32: 2193-9.

20. Dale AC, Midthjell K, Nilsen TI, Wiseth R, Vatten LJ. Glycaemic control in newly diagnosed diabetes patients and mortality from ischaemic heart disease: 20-year follow-up of the HUNT Study in Norway. Eur Heart $J$ 2009; 30: 1372-7.

21. Mannucci E, Monami M, Lamanna C, Gori F, Marchionni N. Prevention of cardiovascular disease through glycemic control in type 2 diabetes: a meta-analysis of randomized clinical trials. Nut Metab Cardiovas 2009; 19: 604-12.

22. Khardori R, Nguyen DD. Glucose control and cardiovascular outcomes: reorienting approach. Front Endocrin 2012; 3: 110.

23. Patel A, MacMahon S, Chalmers J, Neal B, Billot L, Woodward M, et al. Intensive blood glucose control and vascular outcomes in patients with type 2 diabetes. $N$ Engl J Med 2008; 358: 2560-72.

24. Action to Control Cardiovascular Risk in Diabetes Study Group, Gerstein HC, Miller ME, Byington RP, Goff DC, Jr., Bigger JT, Buse JB, et al. Effects of intensive glucose lowering in type 2 diabetes. $N$ Engl J Med 2008; 358: 2545-59.

25. Skyler JS, Bergenstal R, Bonow RO, Buse J, Deedwania P, Gale EA, et al. Intensive glycemic control and the prevention of cardiovascular events: implications of the ACCORD, ADVANCE, and VA diabetes trials: a position statement of the American Diabetes Association and a scientific statement of the American College of Cardiology Foundation and the American Heart Association. Circulation 2009; 119: 351-7.

26. Zhang Y, Lee ET, Devereux RB, Yeh J, Best LG, Fabsitz RR, et al. Prehypertension, diabetes, and cardiovascular disease risk in a population-based sample: the Strong Heart Study. Hypertension 2006; 47: 410-4.

27. Capodanno D, Patel A, Dharmashankar K, Ferreiro JL, Ueno M, Kodali M, et al. Pharmacodynamic effects of different aspirin dosing regimens in type 2 diabetes mellitus patients with coronary artery disease. Circulation Cardiovasc Interv 2011; 4: 180-7.

28. Andersson C, Lyngbaek S, Nguyen CD, Nielsen M, Gislason GH, Kober L, et al. Association of clopidogrel treatment with risk of mortality and cardiovascular events following myocardial infarction in patients with and without diabetes. JAMA 2012; 308: 882-9.

29. Sorensen R, Abildstrom SZ, Hansen PR, Hvelplund A, Andersson C, Charlot M, et al. Efficacy of postoperative clopidogrel treatment in patients revascularized with coronary artery bypass grafting after myocardial infarction. J Am Coll Cardiol 2011; 57: 1202-9.

30. Ajjan RA. Primary and secondary prevention of cardiovascular disease in diabetes with aspirin. Diabetes Vasc Dis Res 2012; 9: 243-4.

31. Stortinget (The Parliament). Lovvedtak 44 (2009-2010). Stortinget, 2010. 
32. Ebbing M. Norsk Register over Hjerte-karsykdom. Hjerteforum 2011; 3: 134-5.

33. Helse- og omsorgsdepartementet. Lov om helseregistre og behandling av helseopplysninger (Helseregisterloven), 2010.

34. Norske hjerteinfarktregister. Velkommen til Norsk hjerteinfarktregister, 2011 [accessed 20123 October]. Available at http://www.helse-midt.no/hjerteinfarktregister.

35. Norsk hjerneslagregister. Velkommen til Norsk hjerneslagregister, 2011 [accessed 20123 October]. Available at http://www.helse-midt.no/hjerneslagregister.

36. Dahl C, Stoltenberg C, Magnus T, Høye A, Skjesol PO, Vassenden A, et al. Gode helseregistre - bedre helse. Strategi for modernisering og samordning av sentrale helseregistre og medisinske kvalitetsregistre 2010-2020. Hovedrapport fra forprosjektet Nasjonalt helseregisterprosjekt. Oslo: Sekretariatet for Nasjonalt helseregisterprosjekt, Folkehelseinstituttet, 2009 [accessed 20123 October]. Available at http://www.nhrp.no.

37. Bakken IJ, Estenstad MG, Gystad SO, Nemeth J, Huse UE. Nytt Norsk pasienteregister gir nye forskningsmuligheter. Nor J Epidemiol 2010; 20: 119-24.

38. Gjersten F. [Cause of death registry: an important data source for medical research.] Tidsskr Nor Lcegeforen 2002; 122: 2551-4.

39. Skatteetaten. Hva gjør folkeregisteret? Skatteetaten, 2010 [accessed 20123 October]. Available at: http://www.skatteetaten.no/no/Artikler/Hvar-gjor-folkeregisteret/.

40. World Health Organization. International Classification of Disease (ICD), 10. Version 2010 [accessed 20123 October]. Available at: http://apps.who.int/classifications/icd10/browse/2010/en.

41. Furu K. Establishment of the nationwide Norwegian Prescription Database (NorPD) - new opportunities for research in pharmacoepidemiology in Norway. Nor J Epidemiol 2008; 18: 129-36.

42. Naess O, Sogaard AJ, Arnesen E, Beckstrom AC, Bjertness E, Engeland A, et al. Cohort profile: cohort of Norway (CONOR). Int J Epidemiol 2008; 37: 481-5.

43. Eidem I, Stene LC, Henriksen T, Hanssen KF, Vangen S, Vollset SE, Joner G. Congenital anomalies in newborns of women with type 1 diabetes: nationwide population-based study in Norway, 1999-2004. Acta Obstet Gynecol Scand 2010; 89: 1403-11.

44. National Medical Quality Register for Adults with Diabetes. Norwegian Diabetes Register for Adults. [accessed 201216 October]. Available at: http://www.noklus.no/Hvatilbyrvi/NorskDiabetesregisterforvoksne/ tabid/85/Default.aspx

45. Ferreiro JL, Angiolillo DJ. Diabetes and antiplatelet therapy in acute coronary syndrome. Circulation 2011; 123: $798-813$.

46. Angiolillo DJ, Fernandez-Ortiz A, Bernardo E, Ramirez C, Sabate M, Jimenez-Quevedo P, et al. Platelet function profiles in patients with type 2 diabetes and coronary artery disease on combined aspirin and clopidogrel treatment. Diabetes 2005; 54: 2430-5. 